\title{
"Confiamos na vossa justiça e caridade": possibilidades de pesquisa em história da assistência à pobreza
}

\author{
"We trust in your justice and charity:" the potential \\ for researching the history of care for the poor
}

\section{Daiane Silveira Rossi $i^{i}$ \\ i Pesquisadora bolsista, Casa de Oswaldo Cruz/Fiocruz. Rio de Janeiro - RJ - Brasil orcid.org/0000-0003-3759-6285 daisrossi@gmail.com}

Recebido em 29 jul. 2018. Aprovado em 4 abr. 2019.
ROSSI, Daiane Silveira. "Confiamos na vossa justiça e caridade": possibilidades de pesquisa em história da assistência à pobreza. História, Ciências, Saúde - Manguinhos, Rio de Janeiro, v.26, supl., dez. 2019, p.235247.

\section{Resumo}

Discute as fontes das intendências municipais, sobretudo as correspondências, como subsídios importantes para a compreensão das relações entre a população pobre e a administração pública durante a Primeira República brasileira. Tem como fio condutor o discurso dos indivíduos que remetiam à municipalidade de Santa Maria cartas em que autodeclaravam pobreza, a fim de investigar quais as estratégias de sobrevivência desse grupo e quais os recursos de assistência pública e privada disponíveis no interior do Rio Grande do Sul. Traçando o perfil da pobreza, analisa as diferenças de gênero, evidenciadas nas justificativas dos pedidos de socorro à intendência.

Palavras-chave: assistência; pobreza; intendência municipal; Primeira República.

\section{Abstract}

This paper discusses the archives of municipal authorities, especially their correspondence, as important inputs for understanding the relationships between the poor population and the public administration during the early republican years in Brazil (1889 to 1930). The discourse of individuals who sent letters to the municipality of Santa Maria in which they claimed to be poor is discussed in order to investigate what survival strategies these people used and what public and private recourse they could turn to in the province of Rio Grande do Sul. Tracing the profile of poverty, the gender differences, marked in the justifications given in the requests for aid from the municipal authority, are analyzed.

Keywords: care; poverty; municipal authorities; First Republic. 
$\mathrm{N}^{2}$ pesquisa desenvolvida para o doutorado, a respeito das práticas de assistência à saúde e à pobreza no interior do Rio Grande do Sul, temos como ponto de partida a análise das relações entre as esferas públicas e privadas. Por meio do nosso objeto de estudo inicial, o Hospital de Caridade de Santa Maria, percebemos essa ligação a partir da investigação sobre os esforços para a fundação dessa instituição. Entre os últimos anos do século XIX e os primeiros do século XX, sua inauguração foi possível por meio da união dos recursos do estado, do município e da sociedade civil. A confluência desses setores, além de fornecer o capital à manutenção da instituição, também foi determinante para delimitar o público que seria atendido, pois sua seleção levava em conta os recursos capitaneados e os órgãos responsáveis. Por exemplo, os pobres atendidos eram custeados por uma subvenção municipal, e os soldados da Brigada Militar - polícia militar local -, principal público recebido nos primeiros anos de funcionamento, eram subsidiados pela subvenção estadual.

Nesse sentido, para entender essas relações e, sobretudo, adentrar o universo da população assistida, uma das principais fontes estudadas foi o Livro de Registro de Entrada e Saída do Hospital de Caridade de Santa Maria (1903-1913), que traz informações sobre os enfermos. Entre os dados que constam nessa documentação estão: nome, sexo, idade, cor, residência, nacionalidade, profissão, diagnóstico, médico responsável pelo atendimento, classificação (pobre, trabalhador da ferrovia, primeira ou segunda classe) data de entrada e saída, motivo da alta, tempo de permanência na instituição e um campo de observações gerais. A riqueza dessa documentação permite ir muito além do cotidiano hospitalar, pois apresenta esse espaço como microcosmo da sociedade ali exposta, a partir do momento que permite mapear um perfil demográfico dessa população.

Para viabilizar o trabalho, ao transcrever a fonte, extraímos informações do Livro de Registros de Entrada e Saída e organizamo-las a partir de categorias de análise numa base de dados no Excel, descrevendo-as ano a ano, entre 1903 e 1913, totalizando 5.224 registros. A partir disso, elaboramos uma vasta gama de perguntas que são respondidas a partir de conexões entre um campo e outro. Por exemplo, foi possível relacionar profissão com diagnóstico e classificação, cor com nacionalidade e residência, idade com tempo de permanência, sexo com cor e profissão, classificação com cor e residência, entre muitos outros cruzamentos possíveis. Essas questões permitem refletir sobre várias temáticas, entre elas: imigração, visto que o segundo maior público, de acordo com a nacionalidade, era o italiano; pós-abolição, considerando que o ano da inauguração do hospital foi 1903 e muitos egressos do cativeiro aparecem nos registros; condições do mundo do trabalho, ao perceber, por exemplo, os acidentes de trabalho como uma causa frequente de internações dos ferroviários; e a pobreza, quando a partir da classificação "pobre" podemos cruzá-la com os demais campos e identificar quem o hospital considerava pertencente a essa categoria.

O grupo classificado como "pobre" destacou-se nessa documentação, visto que, ao longo dos 10 anos investigados, corresponde a mais de 50\% da população atendida no hospital. Em termos numéricos, equivale a 2.727 internações, sendo que alguns indivíduos dão entrada mais de uma vez. Representariam, dessa forma, aproximadamente 2.600 homens e mulheres. Relacionando o contexto local - e sabendo que a cidade de Santa Maria tinha cerca de trinta mil habitantes em 1900 - com os registros do Hospital de Caridade, vemos que nem todos os pobres eram oriundos dessa cidade. Mesmo que representassem $76 \%$, 
ainda temos $24 \%$ residentes em outros municípios do Rio Grande do Sul. Fazendo um cálculo aproximado, menos de duas mil pessoas eram de Santa Maria o que, comparado com o total de moradores, representa uma proporção baixa. Dessa maneira, a pobreza assistida pelo hospital refletia uma parcela bem pequena da população local, o que nos levou a buscar em outras fontes registros que trouxessem mais conhecimentos sobre a recorrência desse grupo ao Hospital de Caridade, entre as demais opções de socorro disponíveis no interior do estado.

Investigamos nos acervos da municipalidade informações referentes a tudo que se relacionasse com a pobreza. Nessa documentação, encontramos correspondências da população endereçadas ao intendente municipal, solicitando isenções dos impostos da décima urbana sob alegação de pobreza. O interessante desse material foi a percepção do que era ser pobre para aquela população. Ao pedir para que o chefe municipal relevasse a dívida do imposto, o indivíduo declarava necessitar dessa dispensa por inúmeros motivos: doença, alienação, viuvez, tutela de filhos menores, orfandade, dificuldades na agricultura de subsistência etc. Dessa maneira, deparamo-nos com outro contexto, do autodeclarante pobre, pertencente a várias categorias, que podem ser diferenciadas da seguinte maneira: (1) pobreza temporária: por exemplo, os que reclamavam não poder pagar o imposto devido a uma má safra, ou pragas de insetos, ou seja, devido a uma situação excepcional que prejudicou sua renda; (2) riscos de cair na miserabilidade: indivíduos que já se encontravam em situação de vulnerabilidade e que, em ocasiões específicas, poderiam se tornar miseráveis; por exemplo, as viúvas pobres, cuja família possuía pouco ou quase nada, cuja situação se agravara com o falecimento do marido que, normalmente, era o único que recebia algum tipo de remuneração; (3) pobreza ocasionada por diferenciação de sexo: notamos que há diferenças claras entre o que era ser um homem pobre e o que significava uma mulher cair na pobreza; (4) alienados: indivíduos que devido a sua condição são considerados miseráveis, no sentido de necessitar apoio do estado.

A seguir, analisaremos a pobreza a partir dessas categorias, com o intuito de demonstrar que as questões propostas para o interior do Rio Grande do Sul podem elucidar outros contextos brasileiros na Primeira República. Isso porque o sistema burocrático, embora com algumas peculiaridades nas constituições estaduais, era bem semelhante. Mas não apenas isso: também o perfil dos indivíduos em situação de pobreza é facilmente comparável, considerando as condições determinantes para que pudessem ser classificados dessa forma. Por isso, é possível estabelecer relações entre outras cidades e estados por meio de dados seriais, por exemplo, extraídos a partir de livros de registros hospitalares e também por meio de uma análise qualitativa sobre quem eram os pobres, investigando o discurso que apresentavam sobre si mesmos por meio de correspondências trocadas com o governo municipal e estadual.

A seguir, iremos exemplificar essa documentação a fim de apresentar possibilidades interpretativas a respeito do socorro aos pobres e suas estratégias de sobrevivência. Destacase a escassez de trabalhos com esse viés, que pretende olhar a pobreza a partir das falas de indivíduos assim considerados e da sua interação com as autoridades públicas. Há algumas pesquisas recentes sobre a assistência no Rio Grande do Sul (Quevedo, 2016; Tomaschewski, 2014), entretanto, centram-se na relação entre as instituições e os governos, estando muitas 
vezes voltadas para questões de financiamento e responsabilidades, e não têm os pobres como protagonistas. Especialmente sobre o Hospital de Caridade de Santa Maria não há nenhuma pesquisa de fôlego, e desconhecemos a existência de algum trabalho historiográfico que analise pedidos de isenção de impostos por intermédio do ponto de vista dos discursos da pobreza.

Para subsidiar esta análise, destaca-se que a documentação pesquisada neste estudo se encontra no Arquivo Histórico de Santa Maria e que comumente arquivos das cidades e dos estados preservam esse tipo de acervo. Trata-se de um vasto conjunto de fontes das intendências municipais que inclui correspondências, documentos oficiais, leis orgânicas, relatórios de secretarias e serviços, orçamentos, recibos, registros de eleitores e de imóveis, entre outros.

\section{Os pobres pedem socorro}

Com base nas fontes disponíveis sobre a administração municipal, encontramos, nas correspondências recebidas pela Intendência de Santa Maria na primeira década do século $\mathrm{XX}$, indícios sobre outro grupo de indivíduos que também fazia parte do universo da pobreza no interior do estado do Rio Grande do Sul. Tratava-se de homens e mulheres que remetiam à municipalidade cartas nas quais se autodeclaravam pobres a fim de conseguir isenções de impostos.

Partimos desse conjunto documental para analisar quais os meios utilizados pelos autodenominados pobres, além do recurso ao hospital, para a sua sobrevivência. Também investigamos como a caridade pública e privada agia para amparar esses indivíduos, evitando que caíssem na miserabilidade. A fim de compreender a pobreza, é necessário entender seu relacionamento com alguns elementos, como a posição social e o status, perpassando questões de gênero, capital social, redes e estratégias. Isso faz dela algo bem mais multifacetado do que uma simples definição baseada em uma economia de recursos, ou seja, em padrões monetários. Concordamos, portanto, com Cynthia Milton (2007, p.XVII) quando afirma que "além de falta de recursos econômicos, a pobreza era uma construção social". ${ }^{1}$

Ao abordarmos a temática da assistência à saúde e à pobreza, tanto no âmbito pessoal quanto em relação ao que acarreta dentro da sociedade, algumas questões se colocam. A primeira delas refere-se à contextualização social e territorial, que pesa por ser um componente geral, afeta diretamente a conjuntura e exige considerações especiais. Sendo assim, para adentrarmos o universo da assistência no interior do sul do Brasil é preciso situar e contextualizar o meio, a fim de que possamos compreender a formação da cidade de Santa Maria (RS), sua população e principais atividades econômicas, o que servirá de base para entender como se formaram os grupos que recorriam à assistência e quem eram aqueles que se organizaram para prestá-la.

Trata-se de uma cidade que, a partir da década de 1870, recebeu grande leva de imigrantes, sobretudo italianos, mas também alemães, que já imigravam desde meados do século XIX. Com a instalação da ferrovia, em 1885, a cidade passa de 13 mil habitantes, em 1885, para trinta mil em 1900, ou seja, mais do que duplica sua população em um período de 15 anos (Rossi, 2017, p.91). 
Enquanto o local recebia novos habitantes, as autoridades precisaram lidar com as demandas que o crescimento populacional causava. Um lugar que, algumas décadas antes, não passava de uma vila rural, nos últimos anos do século XIX estava com ares de cidade grande, na qual centenas de pessoas circulavam todos os dias pela ferrovia, além dos que lá residiam. Aliado ao progresso do crescimento urbano e populacional, o número de pobres aumentava e era a eles que as autoridades precisavam dedicar atenção. A seguir, demonstraremos, com base na documentação do Arquivo Municipal de Santa Maria, como a municipalidade enfrentou uma questão social na Primeira República: como lidar com a pobreza.

$\mathrm{O}$ início da pesquisa no arquivo centrou-se em buscar fontes dos anos anteriores à fundação do Hospital de Caridade (1903) e dos seus primeiros anos de funcionamento, até 1910. Entre 1899 e 1910, localizamos dez caixas com cerca de sessenta tomos, cujos assuntos referiam-se à administração pública: lista de eleitores, contratos, relatórios de higiene, documentação tributária, livros de despesas da intendência, legislação municipal, livro dos contribuintes da limpeza pública, correspondências recebidas, entre outros. Foi nos tomos referentes às correspondências que percebemos um diálogo mais próximo entre a população e a intendência, pois as cartas eram o meio utilizado para recorrer a subsídios, especialmente em momentos mais complicados para a sobrevivência dos signatários ou de suas famílias. Nesse sentido, interessa saber quem eram as pessoas que utilizavam esse mecanismo, por que e em quais situações o faziam.

Investigando as correspondências, encontramos 118 cartas que se relacionam com a prestação de assistência pela intendência, por meio de pedidos de isenção de impostos ou de multas da parte de pessoas que alegavam pobreza e que, por esse motivo, solicitavam a benemerência das autoridades para atenuar suas dívidas. Boa parte dessas correspondências dizia respeito à documentação tributária da décima urbana. Também havia cartas direcionadas aos socorros prestados pela municipalidade, como o caso de pessoas comprovadamente alienadas que seriam enviadas ao Hospício São Pedro, em Porto Alegre. Além disso, algumas cartas diziam respeito a acordos que a intendência firmava com instituições, por exemplo, doações anuais à Santa Casa de Misericórdia e à Faculdade de Medicina de Porto Alegre. Aparecem também outras formas de assistência, como aos presos pobres da Casa de Correção, aos indigentes transportados pela estrada de ferro, às sociedades beneficentes da cidade, e o atendimento aos variolosos e à Enfermaria Militar de Santa Maria.

Nessas cartas, há 81 menções diretas a situações que consideramos referentes à pobreza, as quais categorizamos entre o "grupo dos impostos" e o "grupo das instituições". Dentro delas, identificamos diversos discursos que os indivíduos em situação de pobreza faziam sobre si, autodenominando-se "pobre", "paupérrimo", "em estado de pobreza", "em extrema pobreza", "muito pobre", "doente", "enfermo", "impossibilitado de trabalhar", "indigente" e "em estado de viuvez". As menções à pobreza aparecem mais nas correspondências relativas aos impostos, e isso corresponde a 53\%. No geral, dizem respeito a pessoas que escreviam à intendência alegando pobreza como justificativa para solicitar que fossem relevados seus impostos ou as multas causadas pelo atraso do pagamento destes.

Já nas cartas referentes aos acordos firmados entre a intendência e algumas instituições, há algumas diretamente relacionadas à pobreza, como aquelas trocadas com a Santa Casa de 
Misericórdia de Porto Alegre, o Hospital de Caridade de Santa Maria e o Hospício São Pedro. A comunicação entre elas referia-se a recebidos e cobranças de subvenções repassadas pela municipalidade para o atendimento de seus doentes e alienados pobres, além de relatórios de prestação de contas da assistência realizada. Por meio dessas informações, é possível perceber que existia uma espécie de rede interinstitucional para o provimento da pobreza no Rio Grande do Sul, expressa por acordos de financiamentos e trânsito de pacientes entre as cidades, conforme a necessidade do tipo de atendimento prestado. Por exemplo, como no Hospital de Santa Maria não se admitiam incuráveis e alienados, caso algum deles pedisse socorro àquele espaço, seria transferido ao Hospício São Pedro, e quem arcaria com esses custos seria a intendência municipal, tratando-se de um indivíduo pobre. A estrada de ferro também se insere no mesmo contexto, porque nela se fazia o transporte desses indivíduos entre Santa Maria e Porto Alegre, com custeio público. Outras instituições como o Asilo de Órfãos, a Casa de Correção e uma sociedade beneficente também se referiam direta ou indiretamente aos indigentes sob responsabilidade da intendência.

Somando os dois quadros, conseguimos mapear onde estão citados e quem está falando nos 81 casos que fazem referência direta à pobreza, satisfazendo 68,6\% das cartas levantadas. As demais cartas abordam de maneira mais pontual relações entre a intendência e outras instituições, bem como relatórios de higiene e relatos de surtos epidêmicos na cidade.

Adiante, trataremos com mais atenção do grupo de reclamantes do imposto da décima urbana, a fim de identificar em que medida a população utilizava a autodeclaração de pobreza como um discurso estratégico, além de entender o que esta situação - estar pobre - significava no cotidiano dos remetentes.

\section{Com a palavra, os pobres}

O conjunto de cartas em que identificamos o maior número de autodeclarações de pobreza faz referência à décima urbana, imposto obrigatório sobre todos os imóveis dentro dos limites da área urbana de Santa Maria. Ele estava previsto na legislação municipal, que determinava que "será cobrado 10\% sobre o valor locativo de todos os prédios situados dentro dos limites urbanos do município, seja qual for a sua denominação, forma, uso e material empregado na sua construção" (Regulamento..., 27 nov. 1905). Ou seja, todos aqueles que fossem proprietários de algum imóvel na cidade estavam obrigados a pagar a décima. Sendo assim, quando lemos que uma pessoa se considerava pobre, devemos levar em conta que esse indivíduo, embora argumentasse estar nessa situação, possuía uma propriedade, um bem imóvel.

Ainda que o discurso dos que remetiam cartas à intendência de Santa Maria não estivesse completamente relacionado à manutenção do seu estatuto social, devemos considerar que estamos falando de pessoas que possuíam bens, logo, não estavam totalmente privados de recursos. Ainda assim, em alguns casos, identificamos elementos associados à defesa do status social.

Como um exemplo daqueles que recorreram à intendência a fim de não declinar socialmente, temos o caso do senhor Laurentino Paz, que escreve em 8 de agosto de 1905: 
Laurentino Paz, proprietário da casa situada na rua 24 de maio, n.51, tendo ficado de pagar em tempo a décima urbana, e por isso incorreu na multa correspondente, vem agora respeitosamente solicitar de V.S ${ }^{a}$. a isenção dessa multa 'em vista de estado precário e dificuldades em seu negócio, trabalhando de jornaleiro'. Nestes termos, espera vosso deferimento (Paz, 8 ago. 1905; destaques no original).

Laurentino nos deixa perceber em sua carta que ele possuía um negócio, provavelmente algum tipo de comércio. Porém, por estar passando por dificuldades financeiras, estava trabalhando como jornaleiro, uma profissão provisória. Assim, pedia ajuda para que não incorresse em mais dívidas o que, talvez, lhe ajudaria a se reestabelecer e voltar ao seu trabalho de origem, já que, como jornaleiro, Laurentino estava sob um regime de trabalho temporário, sob demanda, que poderia ser exercido em qualquer lugar e sem nenhum tipo de estabilidade. Identificamos, dessa forma, que no pedido de isenção da multa está inferido um tipo de mobilidade social: o indivíduo que recorre ao apoio da municipalidade passava por um momento em que declinava de ser comerciante para sobreviver de trabalhos temporários. A ajuda da intendência significava um gasto a menos, o que contribuiria para que pudesse recuperar sua posição social. De alguma maneira, Laurentino e aqueles que recorriam à municipalidade possuíam algum capital, fosse econômico ou social, o que permitia que percebessem, no envio de solicitações às autoridades públicas, estratégias possíveis para sua sobrevivência. Nessa perspectiva, objetivamos compreender as estratégias dos indivíduos em situação de pobreza dentro das possibilidades que a assistência no interior do Rio Grande do Sul apresentava, nesse caso, por meio da isenção de impostos concedida pelas autoridades.

Salta aos olhos o expressivo número de mulheres que recorriam à intendência solicitando liberação das multas da décima urbana: das 33 cartas, temos 23 remetentes mulheres, ou seja, 69,6\%. Assim, a maioria das pessoas, quase 70\%, que se definiam como pobres eram mulheres. Esses dados nos levam a concordar com Laurinda Abreu (2014, p.202), que, ao investigar o universo da pobreza no Antigo Regime, afirmou que "a doença, a infância, a velhice e a viuvez, sobretudo feminina, eram as situações que mais convocavam a generosidade das populações, na Europa Ocidental, moldadas pelos valores do cristianismo". Reduzindo a escala de análise ao sul do Brasil na Primeira República, percebemos que os mesmos motivos impulsionavam os indivíduos a recorrer à caridade pública.

Percebendo a clara distinção de gênero no universo da pobreza estudado, podemos destacar que, do montante correspondente a 66,6\% das mulheres, 13 são viúvas $(56,5 \%)$ e, entre elas, 12 (92,3\%) alegam viuvez justificada por mais algum motivo: "estado precário", "estado de pobreza e falta absoluta de meios", "pobre", "doente", "em extrema pobreza". Há um caso pontual que abarca uma dupla questão feminina envolvendo pobreza.

Ernestina Krebs, viúva, residente nesta cidade, vem com a dívida expor a V.S ${ }^{a}$. o seguinte: sendo 'viúva', vivendo com escassos recursos pecuniários, além [disso] tendo em minha 'companhia uma filha solteira', sendo proprietária de uma casa onde mora situada a Praça da República, sem outros meios para minha subsistência, em vista do que vim expor a Vossa Senhoria, venho por este meio respeitosamente pedir o favor de isentar-me do imposto da décima urbana, a que está [sic] sujeita por lei. Santa Maria, 26 de novembro de 1909 (Krebs, 26 nov. 1909; destaques nossos). 
A situação de Ernestina agrava-se porque, além de ser mulher e viúva, também tinha sob sua tutela uma filha solteira. São na verdade duas mulheres que necessitavam do apoio do município para que não caíssem na miserabilidade, pois além da propriedade onde residiam, nada mais possuíam de recursos. Ser viúva e ser solteira são duas características importantes no universo da pobreza, pois as participantes desses grupos formam alguns dos coletivos mais vulneráveis da sociedade.

Quando olhamos para as viúvas comparadas aos viúvos, por exemplo, notamos uma diferença ímpar: eles não teriam agravantes em suas vidas caso suas esposas viessem a óbito, permaneceriam em seus empregos e/ou facilmente conseguiriam casar novamente. Já as mulheres, na viuvez, estavam desamparadas, com ofertas de trabalho muito restritas e com salários precários. No caso de possuírem filhos menores ou filhas solteiras a situação era acentuada porque, além de ser difícil subsidiar o próprio sustento, ainda teriam que alimentar, vestir e proteger seus filhos. Logo, se voltamos ao caso acima analisado, de Ernestina, entendemos os fatores que a levaram a considerar-se sem meios de subsistência, carecendo do socorro público. A resposta a sua carta por parte da intendência, "Deferido, a pecuniária é viúva e pobre", demonstra que as autoridades entendiam essa situação como de necessidade e assumiam a responsabilidade por esse grupo, relevando suas multas e impostos.

O mesmo ocorreu com Maria da Silva (20 jun. 1905), que remete um pedido de isenção das multas da décima urbana, que ficou devendo por dois anos: "Devido ao seu 'estado precário e da viuvez"', deixou de pagar o imposto da décima de sua casa, situada na rua Conde de Porto Alegre, relativa ao segundo semestre de 1903 e 1904, na importância de nove mil réis, inclusive a multa respectiva: "Confiando no vosso espírito justiceiro, pede relevação". A sua carta foi respondida pelo intendente municipal à época, 1905, coronel Dutra Vila (30 jun. 1905), que atestou ter sido "relevada da multa em vista de seu estado de viúva". Assim, temos ao menos dois exemplos em que a intendência entende a viuvez como uma condição na qual era preciso intervir com algum apoio, no caso a isenção de multas da décima.

A vulnerabilidade feminina também está muito presente no discurso de outra viúva, que utiliza o cunhado, Antão Schneider, para redigir a carta e a enviar à Intendência de Santa Maria:

Diz Anna Schneider, viúva de Miguel Schneider, que tendo lhe sido apresentada uma conta dessa Intendência na importância de $51 \$ 240$ réis, vem ponderar o seguinte: que seu finado marido deixou-a em 'extrema pobreza', julgando ser viúva em pedaços de sofrimento deve merecer indulgência sem por isso pedir-vos uma medida de equidade (Schneider, 13 dez. 1909; destaque nosso).

Anna, que talvez não soubesse escrever e por isso pediu o intermédio de alguém da família para ajudá-la com o pedido, apresenta-se em "extrema pobreza". Para ela, perder seu marido, o sustento da casa, era tornar-se alguém que, a partir daquele momento, necessitava da indulgência das autoridades municipais. Nesse sentido, é preciso relativizar e adentrar melhor o universo desses indivíduos antes de afirmar que, apenas por possuir uma propriedade, aquela pessoa não pudesse ser considerada pobre. A viuvez era uma forma 
de mobilidade social negativa, pois colocava a família em situação de vulnerabilidade, fazendo com que a mulher não só recorresse à intendência pedindo que seus impostos fossem perdoados, mas, além disso, alegasse estar em situação extrema, que ameaçava sua sobrevivência.

Outro caso envolvendo as relações femininas, agora não mais de viuvez, foi o de Rafaela Carvani. Em 25 de julho de 1905, escreve à intendência explicando que "na ausência do seu marido, João Carvani, que se acha há meses no Quaraí, vem solicitar a V.S. que seja relevada a multa em que incorre, por não ter pago no tempo a décima de sua casa, situada na rua Dr. Pantaleão" (Carvani, 25 jul. 1905). Na carta que transcrevemos, vemos que o atraso no pagamento da décima urbana ocorreu porque a suplicante estava sem recursos devido à ausência do seu marido que havia meses encontrava-se em uma cidade na fronteira com a Argentina, Quaraí, a cerca de trezentos quilômetros de sua residência.

As condições analisadas até o momento remetem a situações de desprovimento, seja pelo que a viuvez causava na vida da mulher e de sua família, seja pela ausência provisória do marido e pela falta financeira que isso gerava. Assim, temos privações, sobretudo econômicas, que remetem à pobreza. No entanto, há outras carências que também acabavam deixando os indivíduos em situação semelhante, tais como a doença e a velhice. Foi o caso de Maria do Carmo Azambuja (20 dez. 1909), que escreveu em 20 de dezembro de 1909, que "em estado de pobreza, velhice, doença e impossibilidade de trabalhar, vem pedir-vos que releveis a décima e multa conforme conta que lhe foi apresentada". Meses mais tarde, sua solicitação foi legitimada pela tesouraria municipal, a qual reafirmou à intendência que "em obediência a respeitável acima, tenho a informação que a peticionária não tem recursos" (Villa, 17 ago. 1910). Por fim, em agosto de 1910, o intendente deu baixa da dívida.

Outra situação interessante foi a carta de Anna Margarida Lau, que foi remetida por intermédio da madre superiora do Hospital de Caridade de Santa Maria, Justina (14 dez. 1909):

Diz Anna Margarida Lau, que sendo devedora a essa Municipalidade da quantia de $305 \$ 000$ proveniente de seu terreno, décimas urbanas de uma pequena casinha, calçamento e cordões, [e] respectivas multas, vem alegar perante vós o seguinte: que se acha já adiantada em camas, pobre e enferma, sem meio de vida por não poder trabalhar visto seu quase estado de cegueira. Que devido a seu estado de enfermidade foi recolhida ao Hospital de Caridade, sendo removida para Porto Alegre a expensas públicas a fim de operar-se de uma catarata. Que nessas circunstâncias julga-se nas condições de vir pedir-vos a relevação dessa dívida, esperando da vossa justiça. Pede deferimento. Santa Maria, 14 de dezembro de 1909.

O primeiro ponto de destaque direciona-se a quem escreveu a carta: uma irmã franciscana que atuava como funcionária do Hospital de Caridade, responsável pelos doentes. Ela foi mediadora da enferma juntamente à intendência, o que concedia já certa legitimidade ao pedido, pois havia sido remetido por uma autoridade, alguém que respondia por uma instituição que possuía fortes vínculos com a municipalidade, inclusive financeiros, por subvencionar os pobres atendidos no hospital. Ao apresentar a situação da mulher, pobre, doente, sem condições de trabalhar, possivelmente já com bastante idade, considerando a catarata ser uma doença da velhice, essa correspondência expõe a penúria em que se encontrava Anna Margarida, e o pedido feito por intermédio da irmã de caridade atesta 
isso, talvez uma última alternativa para não cair na miserabilidade. Além disso, essa correspondência também demonstra, mais uma vez, a relação entre hospital e intendência, acrescentando, aliás, outro elemento, a Santa Casa de Misericórdia de Porto Alegre, para onde Anna Margarida tinha sido removida com recursos públicos.

Percebemos a exposição de uma rede de recursos com os quais os indivíduos em situação de pobreza poderiam contar, ao menos alguns deles - os que sabiam utilizar essas estratégias a seu favor. Em caso de doença, recorriam ao Hospital de Caridade, onde seu atendimento era custeado por subvenção municipal e, caso necessitassem de uma cirurgia mais complexa, eram remetidos a Porto Alegre, com gastos também financiados. Se alegassem e justificassem pobreza também poderiam recorrer aos subsídios públicos, como Anna Margarida, que, embora possuísse um terreno e uma casa, alegou ser pobre e não ter meios de vida porque não podia trabalhar, dada sua situação ter sido agravada por doença. Portanto, vemos os braços da assistência pública atendendo aos pobres em situação de enfermidade, viuvez ou falta de trabalho.

A doença e a privação do trabalho são pontos em comum, tanto do universo feminino quanto do masculino. Foi o caso de Manuel Pires, que, por intermédio de Manuel do Carmo, enviou um pedido à intendência.

O abaixo declarado achando-se inserido no número dos devedores ao tesouro do município, e sendo 'pobre' e tendo 'numerosa prole' e se achando constantemente 'enfermo', que o priva de trabalhar, se vê na triste contingência de não poder satisfazer em pronto o referido pagamento, por este motivo vem perante vós solicitar a relevação da multa que lhe foi imposta, pede que lhe seja facultado só o pagamento do imposto integral. Santa Maria, 23 de dezembro de 1909 (Carmo, 23 dez.; destaques nossos).

Nessa carta, Manuel também alegou questões de família, "sua numerosa prole", como um elemento que prejudicava sua situação, pois, além de encontrar-se doente, ainda tinha muitos filhos para sustentar. Sendo assim, mesmo possuindo uma residência própria, considerava-se pobre, dadas as condições agravantes. A privação do trabalho aparece como algo caro aos discursos masculinos.

Embora estejamos dedicados à análise da décima urbana, cabe aqui um caso do imposto comercial que elucida outra situação acontecida com um homem, que acaba suplicando ajuda devido à doença na família. Afirmou "deixou de efetuar o pontual pagamento [de sua fábrica de vinho], como é seu costume, devido a contínuas doenças em sua família que o privou de meios para satisfazer o aludido imposto" (Comin, mar. 1906). Buscando pelo nome e sobrenome de "Angelo Comin", o suplicante acima, encontramos na documentação do Hospital de Caridade o registro de Maria Luiza Comin, moradora do mesmo distrito de Angelo, Silveira Martins, casada, internada no hospital pouco tempo depois desse pedido ter sido enviado à intendência. Dois anos mais tarde, em 1908, a mesma mulher reaparece no hospital, dessa vez viúva; em sua doença está descrita como "alienada" e, nas observações feitas pelos médicos, consta que seria transferida para Porto Alegre. Cruzando esses dados, podemos inferir que, possivelmente, Maria Luiza era esposa de Angelo e que a doença que já a afligia em 1906 fosse algo que na época era considerado como alienação, algum tipo de histeria ou, nos termos usados então, "loucura". Por isso, seu marido precisava dedicar 
ainda mais tempo aos seus cuidados, necessitando deixar de lado seu trabalho na fábrica de vinho e, sendo assim, não tinha recursos para pagar a dívida contraída pelo imposto de seu comércio.

É interessante ressaltar que no final da carta enviada por Angelo, ele suplica "confiando na justiça e caridade de Vossa Senhoria, espera favorável deferimento" (Comin, mar. 1906). Ou seja, há o entendimento de que, acatando seu pedido, dada sua situação precária causada pela doença da esposa, estaria a intendência praticando um ato de caridade. Destacamos esse fato para dar crédito a nossa hipótese de que o deferimento dos pedidos de isenção de impostos era um tipo de assistência prestada pelas autoridades municipais aos necessitados que recorriam a ela, justificada por meio das súplicas, principalmente de pobreza, enfermidade e viuvez. Ao acatar essas solicitações, a caridade pública definia e selecionava seu público. Destaca-se, sobretudo, uma diferença de gênero entre os assistidos: enquanto as mulheres recorriam ao socorro público principalmente devido à viuvez, entre os homens o principal motivo era a enfermidade. A solidão, a partir da morte do marido, desampara a mulher, ao passo que a doença empobrecia o homem, pois o privava do trabalho.

\section{Considerações finais}

A partir da discussão elaborada neste artigo, que perpassou a história da assistência, conseguimos compreender as relações expostas entre o universo da pobreza e as autoridades públicas. Ao investigarmos as correspondências trocadas entre uma população que solicitava ajuda e a intendência municipal, evidenciamos o constante intercâmbio entre o universo público e o privado. Essa configuração não se expressa apenas por meio do financiamento do socorro prestado, mas também por intermédio de relações de reciprocidade, nas quais os indivíduos em situação de pobreza criaram discursos sobre si como uma estratégia de barganha. Isso demonstra o poder manifestado por eles ao saber interagir com as autoridades em benefício próprio.

Neste texto observamos um estudo de caso específico para o interior do Rio Grande do Sul. Entretanto, como já destacamos, esse conjunto documental analisado pode ser encontrado em outros contextos brasileiros, afinal, o meio de interlocução do período eram as cartas. Por exemplo, ao identificarmos as mulheres viúvas e solteiras e os homens enfermos como o público principal que recorria à intendência pedindo socorro, estamos respondendo a uma questão fundamental para a história da assistência desde o período moderno: "quem são os pobres?". Esses grupos também nos indicam o perfil dos pobres que utilizavam o pedido de isenção de impostos como uma estratégia de sobrevivência: homens doentes e sem trabalho e mulheres viúvas, solteiras e com filhos menores.

Retomando um ponto que discutimos no início do artigo, sobre os assistidos pelo Hospital de Caridade de Santa Maria, identificamos também as alternativas de assistência prestadas no interior do Rio Grande do Sul. Ou seja, havia diferentes recursos que os pobres poderiam acessar, como o hospital local, a intendência e, como vimos brevemente, outras instituições do Estado, como a Santa Casa de Misericórdia de Porto Alegre e o Hospício São Pedro.

Além disso, destacamos o meio em que a pobreza interagia, elucidando fatores que podem ser analisados nos mais diversos contextos, ao trazermos à tona questões como a presença 
da ferrovia, do crescimento urbano e da imigração como pontos-chave para compreender a emergência da questão social nas cidades brasileiras.

Pontuamos, portanto, a relevância da documentação das intendências municipais para refletir sobre seu diálogo com os pobres por meio das cartas, a interação entre as instituições locais e estaduais, as estratégias de sobrevivência empregadas pelos indivíduos e as de proteção social usadas pelas autoridades públicas durante a Primeira República.

\section{AGRADECIMENTOS}

O presente trabalho foi realizado com apoio da Coordenação de Aperfeiçoamento de Pessoal de Nível Superior (Capes), Brasil. Código de Financiamento 001.

\section{NOTA}

${ }^{1}$ Nessa e nas demais citações de textos publicados em outros idiomas, a tradução é livre.

\section{REFERÊNCIAS}

ABREU, Laurinda.

Emergência das políticas públicas sociais e de saúde pública. Communio: Revista Internacional Católica, v.31, n.2, p.201-208. 2014.

AZAMBUJA, Maria do Carmo.

Carta ao intendente municipal. Fundo Intendência Municipal. Série Correspondências, tomo 51, caixa 10 (Arquivo Histórico Municipal, Santa Maria-RS). 20 dez. 1909.

CARMO, Manuel do. Carta ao cel. Ramiro de Oliveira, intendente municipal. Fundo Intendência Municipal. Série Correspondências, tomo 51, caixa 10 (Arquivo Histórico Municipal, Santa Maria-RS). 23 dez. 1909.

\section{CARVANI, Rafaela.}

Carta ao intendente municipal. Fundo Intendência Municipal. Série Correspondências, tomo 4, caixa 8 (Arquivo Histórico Municipal, Santa Maria-RS). 25 jul. 1905.

COMIN, Angelo.

Carta ao intendente cel. Dutra Vila. Fundo Intendência Municipal. Série Correspondências, tomo 46, caixa 8 (Arquivo Histórico Municipal, Santa Maria-RS). mar. 1906.

JUSTINA, madre.

Carta ao intendente municipal. Fundo Intendência Municipal. Série Correspondências, tomo 51, caixa 10 (Arquivo Histórico Municipal, Santa Maria-RS). 14 dez. 1909.

KREBS, Ernestina.

Carta ao intendente municipal. Fundo Intendência Municipal. Série Correspondências, tomo 51, caixa 10 (Arquivo Histórico Municipal, Santa Maria-RS). 26 nov. 1909.
LIVRO...

Livro de registro de entrada e saída do Hospital de Caridade de Santa Maria. Livro 01. (Arquivo do Hospital de Caridade Dr. Astrogildo de Azevedo, Santa Maria-RS). 1903-1913.

MILTON, Cynthia.

The many meanings of poverty: colonialism, social compacts, and assistance in eighteenth-century Ecuador. Stanford: Stanford University Press. 2007.

PAZ, Laurentino.

Carta ao intendente municipal. Fundo Intendência Municipal. Série Correspondências, tomo 41, caixa 8 (Arquivo Histórico Municipal, Santa Maria-RS). 8 ago. 1905.

QUEVEDO, Éverton Reis.

"Uma mão protetora que os desvie do abismo": Sociedade Portuguesa de Beneficência de Porto Alegre e seu hospital, 1854-1904. São Leopoldo: Oikos; Editora Unisinos. 2016.

\section{REGULAMENTO...}

Regulamento da décima urbana do ano de 1905. Fundo Intendência Municipal. Série Correspondências, tomo 39, caixa 7 (Arquivo Histórico Municipal, Santa Maria-RS). 27 nov. 1905.

ROSSI, Daiane Silveira.

A interiorização da assistência no sul do Brasil durante o início da República: notas iniciais de pesquisa. In: Korndörfer, Ana Paula et al. História da assistência à saúde e à pobreza: olhares sobre suas instituições e seus atores. São Leopoldo: Oikos. p.81-97. 2017.

SCHNEIDER, Anna.

Carta ao intendente municipal. Fundo Intendência Municipal. Série Correspondências, 
tomo 51, caixa 10 (Arquivo Histórico Municipal, Santa Maria-RS). 13 dez. 1909.

SILVA, Maria da.

Carta ao intendente municipal. Fundo Intendência Municipal. Série Correspondências, tomo 40, caixa 8 (Arquivo Histórico Municipal, Santa Maria-RS). 20 jun. 1905.

TOMASCHEWSKI, Cláudia.

Entre o Estado, o mercado e a dádiva: a distribuição de assistência a partir das irmandades da Santa Casa de Misericórdia nas cidades de Pelotas e Porto Alegre, Brasil, c.1847c.1891. Tese (Doutorado em História) - Pontifícia Universidade Católica do Rio Grande do Sul Porto Alegre. 2014.
VILA, Dutra.

Carta em resposta a Maria da Silva. Fundo Intendência Municipal. Série Correspondências, tomo 40, caixa 8 (Arquivo Histórico Municipal, Santa Maria-RS). 30 jun. 1905.

VILLA, Pedro F.

Carta em resposta a Maria do Carmo

Azambuja. Fundo Intendência Municipal. Série Correspondências, tomo 51, caixa 10 (Arquivo Histórico Municipal, Santa Maria-RS). 17 ago. 1910. 